\title{
Maternal and Child Awareness and Expectations of Child Overweight
}

\author{
Anne Brødsgaard ${ }^{\mathrm{a}, \mathrm{b}} \quad$ Lis Wagner $^{\mathrm{b}} \quad$ Birgit Peitersen ${ }^{\mathrm{a}} \quad$ Ingrid Poulsen $^{c} \quad$ Thorkild I.A. Sørensen $^{\mathrm{d}}$ \\ aDepartment of Paediatrics, Copenhagen University Hospital Hvidovre, \\ ${ }^{\mathrm{b}}$ Research Unit of Nursing, Institute of Clinical Research, Faculty of Health Sciences, University of Southern Denmark, \\ 'Research Unit, Department of Neuro-Rehabilitation, TBI Unit, Copenhagen University Hospital, Glostrup, \\ dInstitute of Preventive Medicine, Copenhagen University Hospital, Denmark
}

\section{Keywords}

Case-control study - Mother-child relation .

Childhood overweight · Body size

\section{Summary}

Objective: We investigated mothers' and children's assessments of body weight and their expectations about perceived body size in relation to overweight of the children. Methods: We performed a case-control study of 111 cases of overweight children and 149 controls of non-overweight children (mean age 8.1 years) and their mothers. All were examined and interviewed about their assessment of body weight and their perception of a normal, attractive and acceptable body size. Results: Case children were less able than control children to correctly assess their own body weight ( $p<0.001)$, as were mothers of overweight children (MOC) to assess their children's body weight $(p<0.001)$. The majority of mothers from both groups wished their children to have a normal body size, but $18 \%$ of MOC wished their children to have an overweight body size ( $p<0.013)$. The majority of case children, control children and mothers found a normal body size for boys and girls to be the most attractive and socially acceptable, but more MOC found overweight among boys to be the most attractive $(p=0.006)$. Conclusion: Overweight children and their mothers show increased uncertainty in the assessment of overweight and obesity, but the perception of a normal, attractive and socially acceptable body size is not distorted.

\section{Introduction}

Despite a growing awareness of the dangers of childhood overweight and obesity, there remains a lack of effective prevention and treatment $[1,2]$. Although many initiatives have been attempted by health professionals, there is general acceptance that the problem cannot be solved with the currently available and applied interventions [3]. Two Cochrane reviews dealing with preventing [4] and treating [5] obesity in children addressed the current evidence for diet and exercise interventions to prevent childhood obesity. The interventions were found not to be effective [4], and no treatment programme could be recommended in favour of another [5]. In addition, the difficulties in defining outcomes for effective interventions have made clear-cut recommendations difficult [6].

To be able to counteract the epidemic of childhood obesity and its adverse effects $[3,7,8]$, it is important to understand the parents' opinions about the weight of their children, and it is a key step in forming effective liaisons between health professionals and parents [9]. To understand whether and how mothers play out action to counteract overweight in their children - which we reported in a joint publication [10] - it would be helpful to know whether the mothers are aware of the overweight in their children. Studies from the UK [11, 12], Italy [13], USA [14, 15], Canada [16] and Australia [17, 18] have shown that parents are unconcerned and unaware of their children's weight status as being overweight or obese [11-19]. As long as their children are active and have a healthy diet and/or good appetite, the mothers do not consider them as overweight [19]. Many mothers do not see their overweight children as being different to their peers [17]. A discrepancy between the perceived and actual weight status of

\section{KARGER \\ Fax +497614520714 \\ Information@Karger.de}

www.karger.com
(C) 2011 S. Karger GmbH, Freiburg

$1662-4025 / 11 / 0044-0297 \$ 38.00 / 0$

Accessible online at:

www.karger.com/ofa
Anne Brødsgaard

Department of Paediatrics, Unit 460, Hvidovre University Hospital of Copenhagen Kettegård Allé 30, 2650 Hvidovre, Denmark

Tel. +45 38623129

anne.broedsgaard@hvh.regionh.dk 
the children is seen where some parents are more likely to perceive their children to be underweight than to be obese $[16,20]$. We investigated how the degree of the children's overweight influenced the way mothers and children assessed their own and each other's body weight. We investigated the mothers' and the children's perception of body size, how they wished it to be, and what they considered socially acceptable and attractive.

\section{Material and Methods}

\section{Study Design and Sampling}

We involved mother-child pairs recruited from the Danish National Birth Cohort (DNBC) which comprises information on exposures and other factors during pregnancy and early life that could be linked to healthrelated phenomena occurring throughout life [21]. The original cohort of 101,042 accounted for approximately $30 \%$ of all Danish pregnancies in the period of 1996-2002, enrolled from across the country by their general practitioner [22]. The women were offered 4 computer-assisted telephone interviews twice during the pregnancy (gestational weeks 15 and 30) and twice postpartum (when the children were 6 and 18 months old), with detailed information about both mother and child. A 7-year followup of the children has been conducted through a questionnaire, filled in by the parents. They were asked to register the child's latest measured height in metres and weight in kilograms. The selection of case and control mother-child pairs was based on these reports. Cases and controls were based on whether the children had developed overweight or not, regardless of the mothers weight status. When recruiting for the present study in September 2007, 11,249 children had turned 7 years of age. Cases and controls were invited for a follow-up of the mothers' and the children's current situation.

\section{Inclusion and Exclusion in the Present Study}

In total, 260 mother-child pairs were included in the analysis of the present study. Inclusion criteria were: i) the biological mothers had participated in all 5 interviews in the DNBC; ii) children were singleton term born between 1999-2000, living in Denmark within the Capital Region of Copenhagen, Zealand and Funen, representing both urban and rural areas; iii) children were categorised either as cases or controls according to the International Obesity Task Force (IOTF) reference for children, age and gender adjusted [23], calculated from the children's reported height and weight at the 7-year follow-up; iv) cases were overweight children with body mass index (BMI) age and gender adjusted, corresponding to adult BMI $\geq 25$ [23]; and v) controls were non-overweight children with BMI age and gender adjusted, corresponding to adult BMI $<25$ [23]. Exclusion criteria were: i) children with congenital diseases, malformations, syndromes or chronic diseases; ii) prepubescent children with physical signs of puberty [24]; and iii) mothers with psychiatric diagnoses. After meeting the inclusion and exclusion criteria for the present study, 2,846 pairs were potentially eligible. The principal reason for ineligibility was that mothers had not participated in all 5 examinations. From among the eligible pairs, 471 pairs were randomly selected within candidate case and control groups. Of these, 241 pairs were invited to participate as cases and 230 as controls. Despite taking several actions to minimise withdrawal, 211 pairs withdrew due to reasons illustrated in figure 1. In total, 307 of the 471 pairs participated in the examination $(65 \%)$. Subsequently, 47 were excluded due to a change in BMI status or the onset of puberty, which resulted in $260(55 \%)$ mother-child pairs (119 boys and 141 girls) being finally included in the analysis. Data collection took place from September 2007 to January 2009, when the children were 7-9 years old.

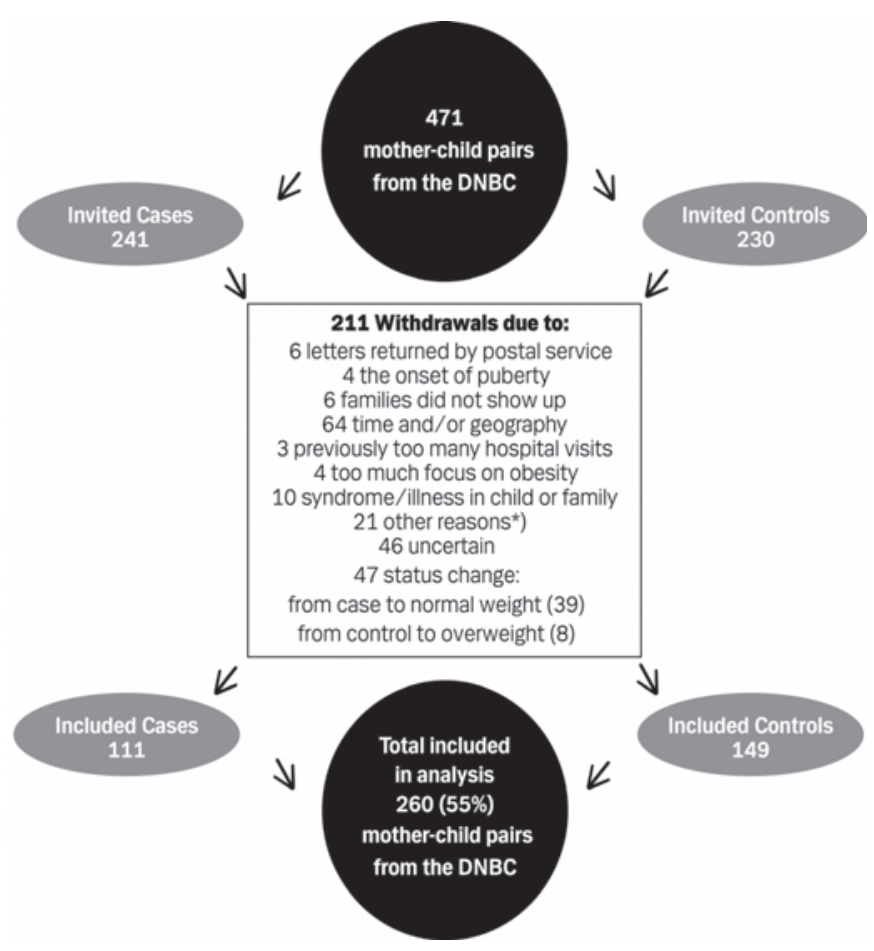

Fig. 1. Distribution of included and withdrawn mother-child pairs $(\mathrm{DNBC}=$ Danish National Birth Cohort; *e.g., father was the legal guardian of the child, child did not wish to participate, national nurse's strike and grandparents' traffic accident).

\section{Examination and Interview}

The investigation took the form of a 2-hour face-to-face interview and a physical examination of the mother and child. To investigate both the mothers' and children's awareness of overweight 'Body Pictograms' (fig. 2) $[14,25-27]$ were used. Both mother and child were asked about their weight and what they wished their weight to be. Their height, weight, waist circumference and hip circumference were all measured. Two researchers, equally trained and experienced in child and family contact, conducted the examinations and interviews (first author $82 \%$ and project nurse $18 \%$ ). Attempts were made to eliminate the possible intra-observer and interobserver discrepancy between the 2 data examiners by validation of measurements and by balancing the allocation of case and control children. Puberty stage of the children was assessed according to Tanner's stage of physical body changes regarding sexual maturation [24]. Mothers were clinically assessed for signs of depression or psychosis. The assessments were based on the researchers' competence and experience (7 and 15 years work, respectively, in paediatric intensive units with screening and identifying families with potential psychiatric diseases). Social-occupational status was based on the current or most recent job within 6 month, or if the mother was attending school, and on the type of education. The category 'high' included mothers in management jobs or in jobs requiring higher education generally more than 4 years beyond high school. 'Middle' included office workers, service workers, skilled manual workers, and 'low' included unskilled workers and unemployed mothers [28].

\section{Body Pictograms}

Line drawings of boy/girl/man/woman figures were used in the children's and mothers' 12 ratings of body size (fig. 2). They were adopted and reproduced with permission from Stunkards [27] and Rand [25, 26], and publisher John Wiley and Sons Ltd. The ratings were classified as underweight (size $1+2)$, normal weight $(3+4)$, slightly overweight $(5)$, moderately overweight $(6+7)$ and very overweight $(8+9)$. Mothers and children were shown 


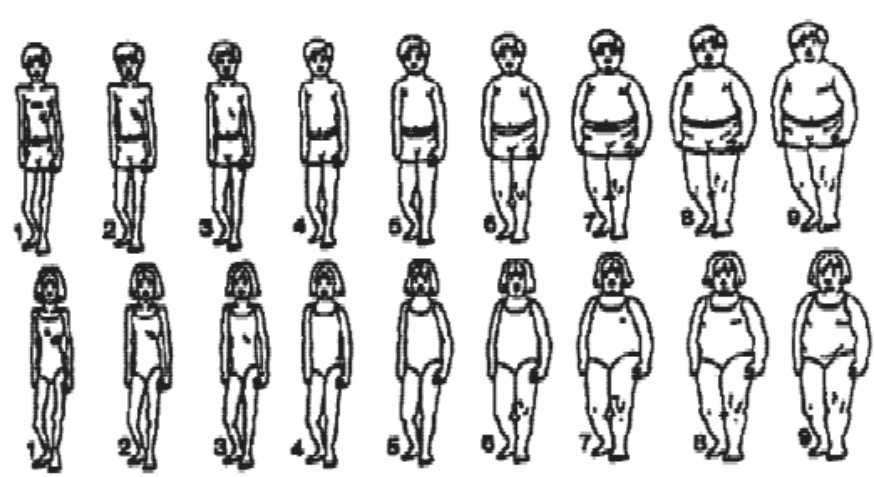

Fig. 2. Body pictograms, adapted from Rand and Resnick [26]. Reproduced with permission from Stunkard, Rand and John Wiley and Sons Ltd. Classification of the ratings were as follows: size $1+2=$ underweight, $3+4=$ appropriate weight (in this paper referred to as normal weight), $5=$ slightly overweight, $6+7=$ moderately overweight, $8+9=$ very overweight

the line drawings of 9 body sizes, representing the children's own age and gender, without indications of the classification. Both groups were asked to choose the body size that they considered best matched their assessment of their own and each other's body size, and how they wished it to be, both for themselves and each other. Subsequently, drawings of boys, girls, men and finally women were shown. Participants were asked to choose the one they found most socially acceptable, and for the boys and girls also the one they assessed as most attractive. The pictograms used for assessing current, desired and ideal body size of children and adults have been reliability tested in other studies. Rand and Resnick [26] found a test-retest agreement of $75 \%$ for children and $73 \%$ for adults, and thus considered validity and reliability for the body pictograms to be good.

\section{Anthropometric Measures}

Body height was measured to the nearest $\mathrm{mm}$ and body weight to the nearest $100 \mathrm{~g}$, determined by standard anthropometric methods [29] using a measuring rod mounted on the wall where the exact measurement gave a result of $+/-2 \mathrm{~mm}$. A digital column scale weight was used to measure the subject without shoes and wearing light clothing [29]. BMI was calculated $\left(\mathrm{kg} / \mathrm{m}^{2}\right)$ and classified as underweight, normal weight, overweight and obese, according to the IOTF reference for children, with adjustment for age and gender using the internationally standardised age- and sexspecific metric proposed by Cole et al. [23]. Waist circumference was measured directly on the skin to within $1 \mathrm{~mm}$, using plastic measuring tapes where the waist was midway between the lowest rib and the iliac crest, with the subject standing and at the end of gentle expiration [29]. Hip circumference was measured at the greater trochanters to the nearest $\mathrm{mm}[30]$. The anthropometric device was checked every day before use.

\section{Statistical Analysis}

Descriptive statistics for the variables of interest were calculated for each group. Means and standard deviations were determined where appropriate, and a threshold for statistical significance was set a priori at 0.05 and with $95 \%$ confidence intervals. The Pearson chi-square test and Fisher's exact test was used to test for differences between the categorical variables. A t-test for unpaired data was used to test for differences between cases' and controls' assessment of body size. The statistical analyses were performed in SPSS software version 16.0/17.0 (SPSS Inc., Chicago, IL, USA).

\section{Ethics}

The study was approved by the DNBC (ref. no. 2007-05), the Danish Data Protection Agency (ref. no. 2007-41-1435) and the Danish National
Committee on Biomedical Research Ethics (ref. no. H-D-2007-0015), and was carried out according to the guidelines of the Helsinki Declaration. All children and mothers were informed about the purpose and procedure, and provided oral and written informed consent. An invitation letter was sent to the mothers asking them to contact us if they wished to participate. If we received no response, the letter was re-sent and followed up by a telephone call where we asked whether they had received the letter, had any questions, and whether or not they wished to participate.

\section{Results}

\section{Anthropometric Measures and Socioeconomic Status}

The mean age for both case and control children was 8.1 years (table 1). The case children had a mean BMI that was 4.37 $\mathrm{kg} / \mathrm{m}^{2}$ higher, a mean waist circumference that was $12.1 \mathrm{~cm}$ wider, and a mean hip circumference that was $10.8 \mathrm{~cm}$ wider than that of the control children (all p values $<0.001$ ) (table 1 ). There were no significant differences between the mothers of overweight children (MOC) and mothers of non-overweight children (MNC) with regard to age and height. MOC had significantly higher weight, BMI, waist (all p values $<0.001$ ) and hip circumferences $(\mathrm{p}=0.001)$ compared with $\mathrm{MNC}$ (table 1). MOC had a lower socio-occupational status than MNC $(\mathrm{p}<0.001)$.

\section{The Children's and Mothers' Assessment of Body Size}

Case and control children assessed their body size significantly different from each other $(\mathrm{p}<0.001)$ (table 2). However, we found $52 \%$ of the case children were not able to assess their own body size correctly when they assessed it to be normal, compared with $84 \%$ of the control children who assessed their body size to be normal and $16 \%$ who assessed it wrongly $(\mathrm{p}<0.001)$ (table 3). When the children were asked how they wished their body size to be, there was less difference between the 2 groups. No significant difference between case and control children was found (table 2). The majority $-84 \%$ cases and $88 \%$ controls - wished for a normal body size, and $18 \%$ cases and $8 \%$ controls wished for a body size that indicated overweight (table 4). No significant difference was found between the 2 groups regarding the most attractive boy and girl, as about $80 \%$ from each group considered the normal body size to be the most attractive. The 2 groups also agreed in their wish for the mother's body size to be normal (80\%). Regarding the most socially acceptable body size, the majority also found this to be in the normal range both for children and adults, but more case children than control children found underweight to be most acceptable, both for boys, girls and women ( $p=0.007$, $\mathrm{p}=0.011$ and $\mathrm{p}=0.003$, respectively) (table 2).

A significant difference between $\mathrm{MOC}$ and $\mathrm{MNC}$ in their assessment of their children's body size was seen $(\mathrm{p}<0.001)$ (table 5). We found $24 \%$ of MOC assess their children's body size wrongly as they assessed their overweight children to have a normal body size, where about $8 \%$ of MNC were not 
Table 1. Descriptive characteristics of participating children and mothers (BMI categories determined per cut-off points as proposed by Cole et al. [23])

\begin{tabular}{|c|c|c|c|}
\hline & $\begin{array}{l}\text { Case overweight/obese child } \\
(\mathrm{n}=111)\end{array}$ & $\begin{array}{l}\text { Control non-overweight child } \\
(\mathrm{n}=149)\end{array}$ & $\mathrm{p}$ value \\
\hline \multicolumn{4}{|l|}{ Child } \\
\hline Mean age, years (SD) & $8.1(0.4)$ & $8.1(0.3)$ & 0.115 \\
\hline Number of girls, $n(\%)$ & $61(55.0)$ & $80(53.7)$ & 0.840 \\
\hline Mean height, $\mathrm{cm}(\mathrm{SD})$ & $134.3(6.0)$ & $131.0(5.5)$ & $<0.001^{\mathrm{a}}$ \\
\hline Mean weight, $\mathrm{kg}(\mathrm{SD})$ & $36.39(4.8)$ & $27.1(3.7)$ & $<0.001^{\mathrm{a}}$ \\
\hline Mean BMI, $\mathrm{kg} / \mathrm{m}^{2}(\mathrm{SD})$ & $20.1(1.6)$ & $15.73(1.4)$ & $<0.001^{\mathrm{a}}$ \\
\hline Mean waist circumference, $\mathrm{cm}$ (SD) & $72.5(5.5)$ & $60.4(4.2)$ & $<0.001^{\mathrm{a}}$ \\
\hline Mean hip circumference, $\mathrm{cm}$ (SD) & $68.9(5.1)$ & $58.1(3.6)$ & $<0.001^{\mathrm{a}}$ \\
\hline \multicolumn{4}{|l|}{ Mother } \\
\hline Mean age, years $(\mathrm{SD})$ & $39.4(4.2)$ & $39.0(4.5)$ & 0.539 \\
\hline Mean height, $\mathrm{cm}(\mathrm{SD})$ & $166.4(5.6)$ & $167.1(5.4)$ & 0.331 \\
\hline Mean weight, $\mathrm{kg}(\mathrm{SD})$ & $75.9(16.0)$ & $68.3(10.1)$ & $<0.001^{\mathrm{a}}$ \\
\hline Mean BMI, $\mathrm{kg} / \mathrm{m}^{2}(\mathrm{SD})$ & $27.4(5.6)$ & $24.5(3.5)$ & $<0.001^{\mathrm{a}}$ \\
\hline Mean waist circumference, $\mathrm{cm}$ (SD) & $96.4(15.9)$ & $91.1(9.4)$ & $<0.001^{\mathrm{a}}$ \\
\hline Mean hip circumference, $\mathrm{cm}(\mathrm{SD})$ & $90.1(15.4)$ & $84.3(8.7)$ & $0.001^{\mathrm{a}}$ \\
\hline Socio-occupational status & & & $<0.001^{\mathrm{a}}$ \\
\hline High, $n(\%)$ & $54(48.6)$ & $98(65.8)$ & \\
\hline Middle, n (\%) & $43(38.7)$ & $49(32.9)$ & \\
\hline Low, n (\%) & 14 (12.6) & $2(1.3)$ & \\
\hline
\end{tabular}

${ }^{\text {aS }}$ Significant.

$\mathrm{SD}=$ Standard deviation .

Table 2. Body sizes assessed by the children

\begin{tabular}{|c|c|c|c|c|c|c|c|}
\hline & \multicolumn{2}{|c|}{ Case $(\mathrm{n}=111)$} & \multicolumn{2}{|c|}{ Control $(n=149)$} & \multirow{2}{*}{$\begin{array}{l}\text { Mean } \\
\text { difference }\end{array}$} & \multirow[t]{2}{*}{$95 \% \mathrm{CI}$} & \multirow[t]{2}{*}{$\mathrm{p}$ value } \\
\hline & mean & $95 \% \mathrm{CI}$ & mean & $95 \% \mathrm{CI}$ & & & \\
\hline The drawing that looks most like your size is & 4.41 & $4.26-4.55$ & 3.94 & $3.83-4.05$ & 0.47 & $0.29-0.63$ & $<0.001^{\mathrm{a}}$ \\
\hline The drawing that looks most like what you wish your size to be & 3.77 & $3.60-3.95$ & 3.84 & $3.73-3-95$ & -0.07 & -0.26 to 0.13 & 0.516 \\
\hline The drawing of the most attractive boy & 3.91 & $3.73-4.09$ & 3.95 & $3.81-4.08$ & -0.04 & -0.26 to 0.18 & 0.744 \\
\hline The drawing of the most attractive girl & 3.77 & $3.58-3.97$ & 3.89 & $3.76-4.01$ & -0.11 & -0.33 to 0.11 & 0.320 \\
\hline The drawing you think is the most socially acceptable boy & 3.77 & $3.57-3.96$ & 4.08 & $3.95-4.21$ & -0.32 & -0.54 to -0.09 & $0.007^{\mathrm{a}}$ \\
\hline The drawing you think is the most socially acceptable girl & 3.59 & $3.37-3.80$ & 3.90 & $3.76-4.04$ & -0.31 & -0.56 to -0.07 & $0.011^{\mathrm{a}}$ \\
\hline The drawing that looks most like your mother's size is & 4.41 & $4.21-4.61$ & 4.25 & $4.11-4.39$ & 0.16 & -0.08 to 0.40 & 0.192 \\
\hline The drawing that looks most like you wish your mother's size to be & 3.77 & $3.59-3.95$ & 3.83 & $3.72-3.93$ & -0.06 & -0.26 to 0.14 & 0.547 \\
\hline The drawing you think shows the most socially acceptable man & 3.72 & $3.52-3.92$ & 3.90 & $3.76-4.03$ & -0.18 & -0.41 to 0.05 & 0.129 \\
\hline The drawing you think shows the most socially acceptable woman & 3.51 & $3.34-3.68$ & 3.84 & $3.71-3.97$ & -0.33 & -0.54 to -0.11 & $0.003^{\mathrm{a}}$ \\
\hline
\end{tabular}

${ }^{\mathrm{a}}$ Significant.

$95 \% \mathrm{CI}=95 \%$ confidence interval.

able to assess their children's body size correctly ( $\mathrm{p}=0.0003$ ) (table 3).The majority of mothers wished for their children to have a normal body size, but $18 \%$ of MOC and $8 \%$ of MNC wished their children to have a body size that equated to overweight $(\mathrm{p}=0.0133)$ (table 4$)$.

More MOC (67\%) than MNC (49\%) correctly considered themselves to have an overweight body size $(\mathrm{p}<0.001)$. The majority of mothers from both groups found normal body size to be the most attractive, both for boys and girls, but more MOC than MNC found overweight among boys to be the most attractive $(\mathrm{p}=0.006)$ (table 5). Mothers' assessment of the most socially acceptable boy and girl showed that the majority from both groups preferred the normal body size. The same was found when the mothers assessed the most socially acceptable man and woman. When the mothers assessed their own body size, a difference between the 2 groups was found 
Table 3. Accuracy of classification of children's body size (BMI categories determined per cut-off points as proposed by Cole et al. [23])
Table 4. Wish for children's body size (BMI categories determined per cut-off points as proposed by Cole et al. [23])

\begin{tabular}{llllll}
\hline & \multicolumn{2}{l}{ Children's own assessment } & & \multicolumn{2}{l}{ Mother's assessment } \\
\cline { 2 - 3 } & $\begin{array}{lllll}\text { case } \\
(\mathrm{n}=111)^{\mathrm{a}}\end{array}$ & $\begin{array}{l}\text { control } \\
(\mathrm{n}=149)^{\mathrm{a}}\end{array}$ & & $\begin{array}{l}\text { MOC } \\
(\mathrm{n}=111)^{\mathrm{b}}\end{array}$ & $\begin{array}{l}\text { MNC } \\
(\mathrm{n}=149)^{\mathrm{b}}\end{array}$ \\
\hline Correct, $\mathrm{n}(\%)$ & $53(48)$ & $125(84)$ & & $84(76)$ & $137(92)$ \\
Wrong, $\mathrm{n}(\%)$ & $58(52)$ & $24(16)$ & & $27(24)$ & $12(8)$ \\
\hline
\end{tabular}

${ }^{\mathrm{a}} \mathrm{p}<0.001$, significant (Fisher's exact test).

${ }^{\mathrm{b}} \mathrm{p}=0.0003$, significant (Fisher's exact test).

$\mathrm{MOC}=$ Mothers of overweight children $; \mathrm{MNC}=$ mothers of non-overweight children.

\begin{tabular}{llllll}
\hline & \multicolumn{2}{l}{ Children's own wish } & & \multicolumn{2}{l}{ Mother's wish for children } \\
\cline { 2 - 3 } & $\begin{array}{l}\text { case } \\
(\mathrm{n}=111)^{\mathrm{a}}\end{array}$ & $\begin{array}{l}\text { control } \\
(\mathrm{n}=149)^{\mathrm{a}}\end{array}$ & & $\begin{array}{l}\text { MOC } \\
(\mathrm{n}=111)^{\mathrm{b}}\end{array}$ & $\begin{array}{l}\text { MNC } \\
(\mathrm{n}=149)^{\mathrm{b}}\end{array}$ \\
\hline Normal, $\mathrm{n}(\%)$ & $93(84)$ & $131(88)$ & & $91(82)$ & $137(92)$ \\
Overweight, $\mathrm{n}(\%)$ & $20(18)$ & $12(8)$ & & $20(18)$ & $12(8)$ \\
\hline
\end{tabular}

${ }^{\mathrm{a}} \mathrm{p}=0.3677$, non-significant (Fisher's exact test).

${ }^{\mathrm{b}} \mathrm{p}=0.0133$, significant (Fisher's exact test).

$\mathrm{MOC}=$ Mothers of overweight children; $\mathrm{MNC}=$ mothers of non-overweight children .

Table 5. Body sizes assessed by the mothers

\begin{tabular}{|c|c|c|c|c|c|c|c|}
\hline & \multicolumn{2}{|c|}{ Case $(n=111)$} & \multicolumn{2}{|c|}{ Control $(n=149)$} & \multirow{2}{*}{$\begin{array}{l}\text { Mean } \\
\text { difference }\end{array}$} & \multirow[t]{2}{*}{$95 \% \mathrm{CI}$} & \multirow[t]{2}{*}{$\mathrm{p}$ value } \\
\hline & mean & $95 \% \mathrm{CI}$ & mean & $95 \% \mathrm{CI}$ & & & \\
\hline The drawing that looks most like your child's size is & 4.95 & 4.81.5.08 & 3.59 & $3.47-3.71$ & 1.36 & $1.17-1.54$ & $<0.001^{\mathrm{a}}$ \\
\hline $\begin{array}{l}\text { The drawing that looks most like what you wish your child's size } \\
\text { to be }\end{array}$ & 4.11 & $4.02-4.20$ & 3.84 & $3.75-3.93$ & 0.27 & $0.14-0.40$ & $<0.001^{\mathrm{a}}$ \\
\hline The drawing of the most attractive boy & 4.08 & $3.98-4.18$ & 3.91 & $3.84-3.99$ & 0.17 & $0.15-0.29$ & $0.006^{\mathrm{a}}$ \\
\hline The drawing of the most attractive girl & 4.06 & $3.97-4.16$ & 3.95 & $3.88-4.03$ & 0.11 & -0.01 to 0.29 & 0.068 \\
\hline The drawing you think is the most socially acceptable boy & 3.89 & $3.78-4.00$ & 3.87 & $3.79-3.94$ & 0.03 & -0.11 to 0.16 & 0.698 \\
\hline The drawing you think is the most socially acceptable girl & 3.73 & $3.60-3.86$ & 3.85 & $3.77-3.93$ & -0.12 & -0.27 to 0.02 & 0.093 \\
\hline The drawing that looks most like your size is & 4.99 & $4.78-5.21$ & 4.47 & $4.32-4.62$ & 0.52 & $0.27-0.77$ & $<0.001^{\mathrm{a}}$ \\
\hline The drawing that looks most like you wish your size to be & 3.72 & $3.61-3.83$ & 3.62 & $3.54-3.71$ & 0.10 & -0.04 to 0.23 & 0.161 \\
\hline The drawing you think shows the most socially acceptable man & 3.83 & $3.78-3.93$ & 3.79 & $3.70-3.88$ & 0.04 & -0.10 to 0.18 & 0.598 \\
\hline The drawing you think shows the most socially acceptable woman & 3.42 & $3.32-3.53$ & 3.50 & $3.41-3-59$ & -0.08 & -0.22 to 0.06 & 0.260 \\
\hline
\end{tabular}

${ }^{\text {a }}$ Significant.

$95 \% \mathrm{CI}=95 \%$ confidence interval.

$(\mathrm{p}<0.001)$ (table 5), but not when it came to their assessment of how they wished it to be. The majority wished for a normal body size.

\section{The Children's and Mothers' Assessment and Expectation of Children's Weight}

MOC and MNC gave an estimate of their children's weight. Overall, a positive correlation $(\mathrm{r}=0.81$ and $\mathrm{r}=0.82$, respectively) was seen between the mothers' estimated weight of the children and the children's measured weight at examination ( $p=0.01)$. However, compared to $5 \%$ of MNC, about $25 \%$ of MOC assessed their children's weight wrongly $(\mathrm{p}<0.0001)$ (table 6). MOC assessed the children's weight to be normal, and not overweight. In comparison, about $22 \%$ of MNC assessed their children's weight to be a little underweight. However, $13 \%$ of these children actually were underweight, and $9 \%$ were normal weight. This indicates that some mothers regardless of the weight status of their children tend to assess their children as thinner than they actually are, and more so for the MOC.

When it came to the way the mothers wished their children's weight to be, more MOC than MNC wished that their children weighed less (54 vs. $6 \% ; p<0.001$ ) (table 7 ). Moreover $20 \%$ of MNC wished their children to weigh more. Many children in 
both groups had no idea about their own weight, or weight in general. Those who had been measured before, e.g. weighed in school, were aware of their own weight. When the children were asked about their wishes for their own weight, the case children wished to a greater extent than the control children that their weight was lower (54 vs. $22 \%$; p < 0.001) (table 7).

Both MOC and MNC had a very good idea of their own weight; a positive correlation $(r=0.99$ and $r=0.98$, respectively) between mothers' estimated weight and measured weight was found $(\mathrm{p}=0.01)$. They were mostly not satisfied with their own weight and wished for their weight to be lower.

\section{Discussion}

The study showed that the overweight children were less able to correctly assess their own body size than were the control children. Compared to $16 \%$ in the control group, $52 \%$ of the case children assessed their body size wrongly. The case children found their body size not to be overweight but normal. This could be explained by their developmental immaturity, or by the fact that their attention had not yet been drawn to their own body and they were therefore not able to correctly assess their own body size. MOC were also less able to correctly assess their children's body size, as opposed to MNC. This finding is in agreement with several other studies showing that mothers were not aware of, or did not acknowledge, their children's body size, weight status or BMI to be above the recommended levels [12,15, 16, 19, 31]. This unawareness could be due to the mothers being unconcerned about their children's weight [12], parental neglect of the child [32], or private explanations like 'bad' genes or other unmanageable

Table 6. Accuracy of mother's classification of their children's weight

\begin{tabular}{llc}
\hline & $\begin{array}{l}\text { MOC } \\
(\mathrm{n}=111)^{\mathrm{a}}\end{array}$ & $\begin{array}{l}\text { MNC } \\
(\mathrm{n}=149)^{\mathrm{a}}\end{array}$ \\
\hline Correct, $\mathrm{n}(\%)$ & $83(75)$ & $141(95)$ \\
Wrong, $\mathrm{n}(\%)$ & $28(25)$ & $8(5)$ \\
\hline
\end{tabular}

${ }^{\mathrm{a}} \mathrm{p}<0.0001$, distributions significantly different (Fisher's exact test)

MOC $=$ Mothers of overweight children;

$\mathrm{MNC}=$ mothers of non-overweight children . psychical or social factors [33]. It could also be that it is just very difficult to make an objective assessment of ones own children. The lack of maternal awareness emphasizes the importance for the health professionals to draw the mothers' attention to the children's beginning overweight.

A key finding in our study is that the majority of both case and control children wished they had a normal body size and weight. However, the overweight children preferred to a higher degree the underweight body size. This could be due to socio-cultural attractiveness and acceptance of overweight. Increased stigmatization of obesity [34] or decreased healthrelated quality of life [35] perhaps experienced by themselves might also have contributed.

The majority of MOC and MNC also wished their children to have a normal body size. Such wishes could be founded in the mothers' possible knowledge about overweight in childhood often being tracked into adolescence and adulthood [36] as well as the increased risk of co-morbidities both in childhood and adulthood $[1,37]$. The mothers may fear that their children are feeling lonely [38], being bullied [39] or humiliated [40]. On the other hand studies found that many mothers did not report any concerns about their overweight children $[16,19]$. Some $54 \%$ of MOC wished for a lesser weight in their children compared to $6 \%$ of MNC. However, this contradicts the fact that many MOC have not recognized the overweight in their children. In this present study, we cannot distinguish between mothers' difficulties in assessing their children's body size, mothers' unawareness of their children's overweight, and mothers' active suppression of the problem.

Some $18 \%$ of MOC wished their children to have an overweight body size. We have no explanation for this, but one reason could be that those families have another standard for normal body size. In accordance with the wishes about body size and weight, the majority of both case and control children and their mothers found a normal body size for boys and girls to be the most attractive, although MOC more than MNC found overweight among boys to be the most attractive. Campbell et al. [17] found that overweight daughters were more likely to elicit maternal concern about current weight than overweight sons.

The MOC and the MNC identified a normal body size for both children and adults to be the most socially acceptable. The participants' perception of what they assumed to be an

Table 7. Wish for children's weight

\begin{tabular}{|c|c|c|c|c|}
\hline & \multicolumn{2}{|c|}{ Children's wish for own weight } & \multicolumn{2}{|c|}{ Mother's wish for children's weight } \\
\hline & $\begin{array}{l}\text { case } \\
(\mathrm{n}=111)^{\mathrm{a}}\end{array}$ & $\begin{array}{l}\text { control } \\
(\mathrm{n}=149)^{\mathrm{a}}\end{array}$ & $\begin{array}{l}\text { MOC } \\
(\mathrm{n}=111)^{\mathrm{b}}\end{array}$ & $\begin{array}{l}\text { MNC } \\
(\mathrm{n}=149)^{\mathrm{b}}\end{array}$ \\
\hline Less, n (\%) & $60(54)$ & $33(22)$ & $60(54)$ & $9(6)$ \\
\hline Same or more, $\mathrm{n}(\%)$ & $51(46)$ & $116(78)$ & $51(46)$ & $140(94)$ \\
\hline
\end{tabular}

${ }^{\mathrm{a}} \mathrm{p}<0.0001$, distributions significantly different (Fisher's exact test).

${ }^{\mathrm{b}} \mathrm{p}=0.001$, distributions significantly different (Fisher's exact test).

$\mathrm{MOC}=$ Mothers of overweight children; $\mathrm{MNC}=$ mothers of non-overweight children . 
attractive and socially acceptable body size corresponded to the normal body size. This is in contrast to some studies suggesting that the rise of obesity in society makes it more likely that a bigger body size will be preferred [12]. Thus, the MOC and the MNC do not have a distorted perception of normal body size.

\section{Limitations and Strengths}

The DNBC included about one third of all pregnant women, and those who participated could be the more resourceful families, especially among families with obesity problems. This implies that our findings may be conservative estimates of the differences between the case and control groups. The same bias could have arisen due to the selection requirement that mothers must have been followed over more than 8 years with several surveys. The DNBC required that the mothers could speak Danish, so very few families with an ethnicity other than Danish were included, which could also have made the differences between case and control group smaller.

Although preliminary results from an ongoing validation study of the offspring's BMI in a sub-sample of the cohort showed that the data generally could be considered to be without systematic errors (C.S. Andersen, unpublished data). The subsequent measurement of the children in the present study showed the well-known tendency to underreport body weight among the more obese segment of the population, also regarding mothers' reports on their children's body weight [41-43]. Therefore, the selection of the case mother-child pairs in particular may not exactly cover the possible case group in the underlying population. Since we selected from the tail of the distribution of reported BMI, the most likely bias due to this problem is that the actual case group is somewhat more overweight than it would have been. On the other hand, the exclusion of 47 (15\%) informants - 39 cases and 8 controls - from the analysis due to status change from belonging to the primarily selected case and control groups suggests that the children had in fact changed their weight during the time between recruitment from the DNBC to examination.

All 3 groups of socio-occupational status were represented in both groups, but with fewest participants exhibiting a low socio-occupational status which is the group most at risk of obesity in the industrialised countries [1]. However, whether this difference in itself - i.e. independent of MOC and MNC status - plays a role in the relationships investigated here, is beyond the scope of the present study.

\section{Perspectives}

The study design was a cross-sectional case-control design, where we investigated the mothers' and children's perception at the same time as their status as cases or controls in terms of their body weight. Therefore, we cannot interpret the differences between the groups in awareness and expectation as features that may have preceded and possibly caused the development of the case status. However, a recent review of multiple risk factors of weight gain in childhood suggested that parents' misperception of their children's weight may be a risk factor on its own [44].

It may be worth addressing, both clinically and in future research, parental awareness of the children's weight, including questions about physical limitations and teasing of children, instead of addressing weight focus alone as suggested by Jain et al. [19]. Furthermore, parental awareness should be addressed early in the children's lives, as we found the differences between cases and controls to exist as early as age 7-9. When mothers fail to recognise the overweight status of their children, primary health care nurses and doctors in charge of the children's health, including specialised paediatricians, may help these parents to correct their misperception [45]. On this background, the findings in our study should be considered as a benchmark from which to look to the future management of the obesity problem in childhood.

In conclusion, we have shown that both case children and case mothers display increased uncertainty in correctly assessing their overweight and obese children. The perception of normal body size is not distorted, as both case and control children and their mothers mainly wish for a normal body size and mainly found others with a normal body size to be the most attractive and socially acceptable.

\section{Acknowledgements}

We thank the children and their mothers who participated in the study, paediatric project nurse Karina Larsen for her contributions to data collection and data keying, statistician Claus Holst for supervising the analysis, and Lorna Campbell, M.A., PGCE, for careful and competent text editing of the manuscript. Financial support: Lundbeck foundation/ UCSF, Åse and Ejnar Danielsens Foundation, Nurses Research Foundation, Hvidovre Hospital Research foundation, Rosalie Petersens Foundation, Beckett-Foundation, King Christian $\times$ Foundation, Else Poulsens memorial award. Books donated for the children: Egmont Comics Publisher, Carlsen A/S, Klematis A/S, Banner and Korch. This study is part of the activities of the Danish Obesity Research Centre, DanORC (www.danorc.dk).

\section{Disclosure Statement}

The authors declare no conflict of interest and are solely responsible for the content and writing of this paper. 


\section{References}

1 Lobstein T, Baur L, Unuy R: Obesity in children and young people: a crisis in public health. Obesity Reviews 2004;5:4-84.

2 Wang Y, Lobstein T: Worldwide trends in childhood overweight and obesity. Int J Pediatr Obes 2006;1:11-25.

3 WHO: European Ministerial Conference on Counteracting Obesity. Diet and Physical Activity for Health. Istanbul, Turkey, 2006. European Charter on Counteraction Obesity. WHO, 2006, pp. 1-5.

4 Summerbell CD, Waters E, Edmunds L, Kelly SAM, Brown T, Campbell KJ: Interventions for preventing obesity in children. Cochrane Database Syst Rev 2005;(3):CD001871.

5 Oude Luttikhuis H, Baur L, Jansen H, Shrewsbury VA, O'Malley C, Stolk RP, Summerbell CD: Interventions for treating obesity in children. Cochrane Database Syst Rev 2009;(1):CD001872.

6 Doak C, Heitmann BL, Summerbell C, Lissner L: Prevention of childhood obesity - what type of evidence should we consider relevant? Obes Rev 2009;10:350-356.

7 Jackson-Leach R, Lobstein T: Estimated burden of paediatric obesity and co-morbidities in Europe. Part 1 . The increase in the prevalence of child obesity in Europe is itself increasing. Int $\mathrm{J}$ Pediatr Obes 2006;1:26-32.

$>8$ Lobstein T, Jackson-Leach R: Estimated burden of paediatric obesity and co-morbidities in Europe. Part 2. Numbers of children with indicators of obesity-related disease. Int J Pediatr Obes 2006;1:33-41.

9 Jackson D, McDonald G, Mannix J, Faga P, Firtko A: Mothers' perceptions of overweight and obesity in their children. Aust J Adv Nurs 2005;23:8-13.

10 Brødsgaard A, Wagner L, Peitersen B, Poulsen I, Sørensen T: Child overweight - mothers' competence to take action. Obes Facts 2011;4(4):305-311.

11 Carnell S, Edwards C, Croker H, Boniface D, Wardle J: Parental perceptions of overweight in 3-5 y olds. Int J Obes (Lond) 2005;29:353-355.

12 Jeffery AN, Voss LD, Metcalf BS, Alba S, Wilkin TJ: Parents' awareness of overweight in themselves and their children: cross sectional study within a cohort (EarlyBird 21). BMJ 2005;330:23-24.

13 Genovesi S, Giussani M, Faini A, Vigorita F, Pieruzzi F, Strepparava MG, Stella A, Valsecch MG: Maternal perception of excess weight in children: a survey conducted by paediatricians in the province of Milan. Acta Paediatr 2005;94:747-752.

14 Eckstein KC, Mikhail LM, Ariza AJ, Thomson JS, Millard SC, Binns HJ: Parents' perceptions of their child's weight and health. Pediatrics 2006;117:681690.

15 Maynard LM, Galuska DA, Blanck HM, Serdula MK: Maternal perceptions of weight status of children. Pediatrics 2003;111:1226-1231.

16 He M, Evans A: Are parents aware that their children are overweight or obese? Do they care? Can Fam Physician 2007;53:1493-1499.
Campbell MW, Williams J, Hampton A, Wake M: Maternal concern and perceptions of overweight in Australian preschool-aged children. Med J Aust 2006;184:274-277.

18 Crawford D, Timperio A, Telford A, Salmon J: Parental concerns about childhood obesity and the strategies employed to prevent unhealthy weight gain in children. Public Health Nutr 2006;9:889895.

19 Jain A, Sherman SN, Chamberlin LA, Carter Y, Powers SW, Whitaker RC: Why don't low-income mothers worry about their preschoolers being overweight? Pediatrics 2001;107:1138-1146.

20 Scholtens S, Brunekreef B, Visscher TL, Smit HA, Kerkhof M, de Jongste JC, Gerritsen J, Wijga AH: Reported versus measured body weight and height of 4-year-old children and the prevalence of overweight. Eur J Public Health 2007;17:369-374.

21 Olsen J, Melbye M, Olsen SF, Sorensen TI, Aaby P, Andersen AM, Taxbol D, Hansen KD, Juhl M, Schow TB, Sorensen HT, Andresen J, Mortensen EL, Olesen AW, Sondergaard C: The Danish National Birth Cohort - its background, structure and aim. Scand J Public Health 2001;29:300-307.

22 Olsen SF, Mikkelsen TB, Knudsen VK, OrozovaBekkevold I, Halldorsson TI, Strom M, Osterdal ML: Data collected on maternal dietary exposures in the Danish National Birth Cohort. Paediatr Perinat Epidemiol 2007;21:76-86.

23 Cole TJ, Bellizzi MC, Flegal KM, Dietz WH: Establishing a standard definition for child overweight and obesity worldwide: international survey. BMJ 2000;320:1240-1243.

24 Tanner JM: Growth and maturation during adolescence. Nutr Rev 1981;39:43-55.

25 Rand CS, Wright BA: Continuity and change in the evaluation of ideal and acceptable body sizes across a wide age span. Int J Eat Disord 2000;28:90-100.

26 Rand CS, Resnick JL: The 'good enough' body size as judged by people of varying age and weight. Obes Res 2000;8:309-316.

27 Stunkard AJ, Sorensen T, Schulsinger F: Use of the Danish Adoption Register for the study of obesity and thinness. Res Publ Assoc Res Nerv Ment Dis 1983;60:115-120.

$28 \mathrm{~N} \varnothing \mathrm{hr}$ E: Obesity in Pregnancy. Epidemiological studies based on the Danish National Birth Cohort. Faculty of Health Sciences, University of Aarhus, 2005.

29 WHO: Training and Practical Guides - Guide to Physical Measurements. WHO, 2008.

30 Wedderkopp N: Athersclerotic Cardiovascular Risk Factors in Danish Children and Adolescents. Institute of Sport Science and Clinical Biomechanics, Faculty of Health Sciences, University of Southern Denmark, 2001, pp. 1-63.

31 Lindelof A: Childhood obesity - the family's perspective; in Lombrog KSL, Spirig R, Zydziunaité V, Wagner L (eds): Obesity: A Threat to Health How can Nursing Research Contribute to Prevention and Care? WENR - Workgroup of European Nurse Researchers, 2006, pp. 23-36.
32 Lissau I, Sorensen TI: Parental neglect during childhood and increased risk of obesity in young adulthood. Lancet 1994;343:324-327.

33 Lindelof A: Overvægtige børn og deres forældres oplevelse og forståelse af barnets overvægt (Overweight children and their parents experiences and understanding of the child's overweight). Ugeskr Læger 2005;167:163-165.

34 Latner JD, Stunkard AJ: Getting worse: the stigmatization of obese children. Obes Res 2003;11: 452-456.

35 Williams J, Wake M, Hesketh K, Maher E, Waters E: Health-related quality of life of overweight and obese children. JAMA 2005;293:70-76.

36 Whitaker RC, Wright JA, Pepe MS, Seidel KD, Dietz WH: Predicting obesity in young adulthood from childhood and parental obesity. N Engl J Med 1997;337:869-873.

37 Reilly JJ, Kelly J: Long-term impact of overweight and obesity in childhood and adolescence on morbidity and premature mortality in adulthood: systematic review. Int J Obes (Lond) 2011;35:891-898.

38 Meriaux BG, Berg M, Hellstrom AL: Everyday experiences of life, body and well-being in children with overweight. Scand J Caring Sci 2010;24:14-23.

39 Lumeng JC, Forrest P, Appugliese DP, Kaciroti N, Corwyn RF, Bradley RH: Weight status as a predictor of being bullied in third through sixth grades. Pediatrics 2010;125:e1301-e1307.

40 Murtagh J, Dixey R, Rudolf M: A qualitative investigation into the levers and barriers to weight loss in children: opinions of obese children. Arch Dis Child 2006;91:920-923.

41 Garcia-Marcos L, Valverde-Molina J, SanchezSolis M, Soriano-Perez MJ, Baeza-Alcaraz A, Martinez-Torres A, Perez-Fernandez V, GuillenPerez JJ: Validity of parent-reported height and weight for defining obesity among asthmatic and nonasthmatic schoolchildren. Int Arch Allergy Immunol 2006;139:139-145.

42 Merrill RM, Richardson JS: Validity of selfreported height, weight, and body mass index: findings from the National Health and Nutrition Examination Survey, 2001-2006. Prev Chronic Dis 2009;6:A121.

43 Huybrechts I, De Bacquer D, VanTrimpont I, De Backer G, De Henauw S: Validity of parentally reported weight and height for preschool-aged children in Belgium and its impact on classification into body mass index categories. Pediatrics 2006;118:2109-2118.

44 Doolen J, Alpert PT, Miller SK: Parental disconnect between perceived and actual weight status of children: a metasynthesis of the current research. J Am Acad Nurse Pract 2009;21:160-166.

45 Etelson D, Brand DA, Patrick PA, Shirali A: Childhood obesity: do parents recognize this health risk? Obes Res 2003;11:1362-1368. 